\title{
раздел ПРАВОВЕДЕНИЕ
}

DOI: 10.33184/bulletin-bsu-2019.3.39

\section{ЗЛОУПОТРЕБЛЕНИЕ ГРАЖДАНСКИМИ ПРОЦЕССУАЛЬНЫМИ ПРАВАМИ В ГРАЖДАНСКОМ ПРОЦЕССЕ}

\author{
(C) Г. А. Аминова \\ Башкирский государственный университет \\ Институт права \\ Россия, Республика Башкортостан, 450005 г. Уфа, ул. Достоевского, 131. \\ Тел.: +7 (927) 6399189. \\ *Email: guzel10.09@mail.ru
}

\begin{abstract}
В статье проводится анализ наиболее распространенный ситуаций, когда судьи при рассмотрении заявлений злоупотребляют своими правами. Это происходит довольно часто, поэтому законодателям следует обратить внимание на данную проблему. Статья указыввает на моменты, в которых имеются правовые пробелы.
\end{abstract}

Ключевые слова: злоупотребление правами, решение суда, процессуальное право, судебный проиесс, ответственность, санкиия, недобросовестность.

\section{Введение}

Обычно, когда говорят о злоупотреблении правом, имеются в виду неправомерные действия со стороны участников судебного процесса. Однако не меньший интерес представляет злоупотребление правом со стороны самого суда.

Отрадно, что для доктрины в Проекте изменений в ГК РФ, разработанных на основе Концепции развития гражданского законодательства, подготовленной на основании Указа Президента Российской Федерации от 18 июля 2008 г. №1108 «О совершенствовании Гражданского кодекса Российской Федерации», предлагается весьма серьезная корректировка запрета на злоупотребление правами - а именно, умышленное, т.е. совершенное с намерением причинить вред или совершенное в обход закона, что также указывает на умысел. Однако, к сожалению, изменений в ГК РФ пока так и не последовало.

\section{Анализ}

Итак, суд - это обособленный орган, не зависимо ни от кого решающий различные споры правового характера. Судебные решения, вступившие в законную силу, обязательны для исполнения всеми гражданами, органами и должностными лицами. К сожалению, в настоящее время в Российской федерации выносится большое количество решений, которые впоследствии невозможно исполнить. Казалось бы, на первый взгляд, что невозможность исполнения связана с действиями и статусом сторон производства. Однако на деле нередко выходит так, что само решение не может быть исполнено по причине отсутствия в нем логики. Подобные решения выносятся без должного рассмотрения судом заявлений, что можно рассматривать как один из вариантов злоупотребления правом самим судом.
Другой пример - решение суда первой инстанции не соответствует правовым нормам. Среди населения бытует мнение, что судьи берут взятки, имеют иной интерес в исходе дела. Даже если подобные высказывания не брать во внимание, итог все равно получается таков, что судьи злоупотребляют своим правом.

Казалось бы, что подобного быть не должно. Однако на деле получается не все так просто. Рассмотрим наиболее частые ситуации злоупотребления правом со стороны суда и попробуем разобраться, почему же они возникают и можно ли от них избавиться.

Иногда бывают явные ошибки суда, когда, не разобравшись в ситуации, суд выносит необоснованное решение, что в итоге и приводит к невозможности его исполнить. К примеру, применение процессуальных средств воздействия на лиц, участвующих в процессе, должно быть разумным и целесообразным. Поэтому суд и участники процесса должны проявлять процессуальную добросовестность. Суд не должен рассматривать беспредметные иски или бесконечно откладывать судебные заседания из-за неявки сторон, свидетелей или адвокатов, умышленно затягивающих процесс.

Вместе с тем нельзя считать всегда обоснованными наиболее часто встречающиеся судебные сообщения и частные определения судов по неявке представителей и самих в суд или опоздания в судебные заседания.

При рассмотрении таких сообщений выясняется, что действительно есть факты, когда стороны по небрежности (забыл, не записал), а иногда и умышленно затягивают рассмотрение дела судом, но в ряде случаев суды даже не стремятся узнать причины неявки. Не менее острой остается проблема, когда представитель стороны не является в судебное заседание из-за занятости в другом процес- 
се, предупреждает суд заранее, что у него назначен другой процесс, но судья, не учитывая это, все равно назначает судебный процесс на то же время. Подобные действия вполне можно считать злоупотреблением правом со стороны суда. Конечно, при желании решение, вынесенное в подобной ситуации, можно отменить или изменить. Однако для этого необходимо время, а оно не всегда имеется у сторон и их представителей.

По конкретным категориям споров участвующие в деле лица предоставляют конкретные доказательства, которые в соответствии со сложившейся судебной практикой суд принимает как относимые, допустимые, даже достоверные и в совокупности достаточные для разрешения того или иного спора, однако нарушая тем самым ч. 2 ст. 67 ГПК РФ, в соответствии с которой никакие доказательства не имеют для суда заранее установленной силы.

Например, для доказывания факта дорожнотранспортного происшествия (далее по тексту ДТП) лицами, участвующими в деле, представляются в материалы дела справка о ДТП, схема ДТП, постановление по делу об административном правонарушении или определение об отказе в возбуждении дела об административном правонарушении - материалы, составляемые сотрудниками ГИБДД. Суд безусловно принимает такие доказательства как относимые, допустимые, достоверные и достаточные для установки факта ДТП. Хотя нередко такие доказательства противоречат реальному положению вещей. И если суд не сомневается в достоверности, а в последствии оказывается, что представленные доказательства оказались подложными, - действия суда можно рассматривать как злоупотребление правом принимать решение по внутреннему убеждению.

Но самой распространенной ситуацией остается злоупотребление правом со стороны суда при направлении корреспонденции. Рассмотрим простой пример. Судья по результатам рассмотрения выносит определение об оставлении поданного искового заявления без движения и предоставляет заявителю какое-то время для устранения выявленных недостатков. Все вроде в рамках закона, поскольку именно так необходимо поступить для выполнения всех требований процессуального права. Как правило, эти определения после этого в максимально сжатые сроки передаются заявителю письмом по почте, либо звонком ему с тем, чтобы он явился в суд и получил определение. Злоупотребляющие правом же судьи ждут момент, когда срок для устранения выявленных недостатков закончится, и лишь после этого отправляют по почте вынесенное определение об оставлении заявления без движения, в это же время вынося определение о возврате иска, поскольку заявитель не устранил в предоставленный срок недостатки. Доходит до того, что определение об оставлении заявления без движения направляется в одном конверте вместе с определением о возврате иска в связи с не устранением недостатков. В итоге истцу приходится подавать иск заново, уплачивая новую госпошлину.

Ранее Судебная коллегия по гражданским делам Верховного Суда РФ в Определении от 3 февраля 2015 г. №32-КГ14-17 пришла к выводу о том, что злоупотребление правом состоит в осуществлении субъективного права в противоречии с его назначением, о чем свидетельствует тот факт, что «субъект поступает вопреки правовой норме, предоставляющей ему соответствующее право; не соотносит свое поведение с интересами общества и государства; не исполняет корреспондирующую данному праву юридическую обязанность».

\section{Выводы}

Как показал проведенный нами анализ, отдельные типы злоупотреблений процессуальными правами в гражданском судопроизводстве, возникающие со стороны суда, достаточно разнообразны. Это в очередной раз подтверждает нашу мысль, что практически каждое субъективное право может быть изменено недобросовестным лицом в случае его использования. Классификация различного рода злоупотреблений правом в гражданском процессе по предметному признаку дала нам возможность последовательно рассмотреть злоупотребления правом, связанные с несением судебных расходов; с определением подведомственности и подсудности гражданского дела; злоупотребления при формировании состава суда; связанные с течением процессуальных сроков, с извещением участников гражданского процесса; злоупотребления правом в приказном производстве; при обеспечении исковых требований; при разбирательстве дела в суде первой инстанции; при окончании гражданского процесса без вынесения решения; злоупотребления при пересмотре судебных постановлений в апелляционном, кассационном, надзорном порядке и по вновь открывшимся обстоятельствам, а также злоупотребления правом при производстве, связанном с исполнением судебных постановлений. С данными формами злоупотребления необходимо постоянно бороться на уровне государства, ведь суд является полностью независимой структурой и принимает все решения исключительно по собственному убеждению, однако принятие незаконного решения приводит к крайне печальным последствиям, от которых страдают простые люди, желающие найти в суде правду. 


\section{ЛИТЕРАТУРА}

1. СНГ: реформа гражданского процессуального права: матлы междунар. конф. /под общ. ред. М. М. Богуславского, А. Трунка. М., 2016.

2. Садиков О. Злоупотребление правом в Гражданском кодексе России // Хозяйство и право. №2. 2016.
3. Липинский Д. А. Проблемы юридической ответственности / под ред. Р. Л. Хачатурова. СПб., 2013.

4. Крусс В. И. Актуальные аспекты проблемы злоупотребления правами и свободами человека // Государство и право. 2017. №7.

5. Ерошенко А. А. Осуществление субъективных прав в противоречии с их назначением // Правоведение. 2014. №4.

Поступила в редакиию 15.04.2019 2. 
DOI: $10.33184 /$ bulletin-bsu-2019.3.39

\title{
CIVIL PROCEDURE RIGHTS IN THE CIVIL PROCESS
}

\author{
(C) G. A. Aminova \\ Bashkir State University, Institute of Law \\ 131 Dostoevsky Street, 450055 Ufa, Republic of Bashkortostan, Russia.
}

\author{
Phone: +7 (927) 6399189. \\ Email: guzel10.09@mail.ru
}

This author of the article analyzes the most common situations where judges, when reviewing applications, abuse their rights. This happens quite often, so lawmakers should pay attention to this problem. The article points out the related legal gaps. Usually, when people talk about abuse of the right, they mean illegal actions on the part of the participants in the judicial process. However, the abuse of the right by the court itself is also of high interest. It is gratifying that serious changes for regulation of abuse of rights (namely, intentional abuse, i.e. committed with intent to cause harm or bypassing the law, which also indicates intent) are planned in the Draft of amendments to the Civil Code of the Russian Federation, developed on the basis of the Civil Law Development Concept, prepared on the basis of the Decree of the President of the Russian Federation of July 18, 2008 No. 1108 "On Improvement of the Civil Code of the Russian Federation". However, unfortunately, no changes have yet been made in the Civil Code of the Russian Federation. The court is a separate body, regardless of who decides various legal disputes. Court decisions that entered into force are binding on all citizens, authorities, and officials. Unfortunately, at present a large number of decisions in the Russian Federation are being made that cannot be executed. It would seem, at first glance, that the impossibility of execution is connected with the actions and status of the parties to the proceedings. However, in fact, it often happens that the decision itself cannot be executed due to the absence of inner logic. Such decisions are made by the court without proper consideration of applications, which can be considered as one of the options for abusing the right by the court itself.

Keywords: abuse of rights, court decision, procedural law, litigation, responsibility, sanction, bad faith.

Published in Russian. Do not hesitate to contact us at bulletin_bsu@mail.ru if you need translation of the article.

\section{REFERENCES}

1. SNG: reforma grazhdanskogo protsessual'nogo prava: mat-ly mezhdunar. konf. /pod obshch. red. M. M. Boguslavskogo, A. Trunka. Moscow, 2016.

2. Sadikov O. Khozyaistvo i pravo. No. 2. 2016.

3. Lipinskii D. A. Problemy yuridicheskoi otvet-stvennosti [Legal liability issues]. Ed. R. L. Khachaturova. Saint Petersburg, 2013.

4. Kruss V. I. Gosudarstvo i pravo. 2017. No. 7.

5. Eroshenko A. A. Pravovedenie. 2014. No. 4.

Received 15.04.2019. 